\title{
Adaptation of Promising Rice Genotypes for Broadcast Aus Season
}

\author{
B Karmakar1, M A A Mamun², M S Rahman³, M A Islam¹, M R Islam¹, M H R Mukul1, \\ Shamsunnaher ${ }^{1}$, A Zahan ${ }^{1}$, R Barua ${ }^{1}$, M R Biswash ${ }^{1}$, S Parveen ${ }^{1}$, \\ S Akter ${ }^{4}$ N Y Shaikh ${ }^{5}$ and B Ahmed ${ }^{1}$
}

\begin{abstract}
Rice cultivation in Aus season is eco-friendly and essential for sustainable food security of Bangladesh utilizing rain water rather than extracting underground water. Four rice genotypes (BR6855-3B-12, BR6855-3B-13, BR6848-3B-12 and BR6976-2B-11-1) along with check variety BRRI dhan 43 were evaluated at farmers' field during broadcast Aus season. The objectives were to investigate the adaptability of the rice genotypes and find out promising genotype(s) for Broadcast Aus rice. The experiment was conducted at farmers' field in eight agro-ecological zones of Bangladesh. Randomized complete block design (RCB) was used with three replications. Standard and uniform management practices were followed for all the locations. Data were taken on grain yield, days to $80 \%$ maturity, plant height, panicles $\mathrm{m}^{-2}, 1000$-grain weight, grains panicle ${ }^{-1}$, spikelet sterility (\%), Phenotypic acceptance at vegetative and maturity stage, pest incidence; feedback of farmers and extension personnel. Genotypes, environments and interaction of genotypes by environments had significant effect on grain yield, yield components and agronomic parameters. Analysis of variance indicated that there were significant differences between the check (control) and improved genotypes except the genotype BR6976-2B-11-1 which was similar with the check BRRI dhan 43 for all parameters. Correlation analysis was also performed to establish extent of association between yield and major yield components. Grain yield positively and significantly correlated with the agronomic parameters except spikelet sterility. Across the locations, BR6848-3B-12 produced significantly the highest grain yield $\left(4.88 \mathrm{t} \mathrm{ha}^{-1}\right)$ at Feni while the lowest grain yield $\left(1.58 \mathrm{t} \mathrm{ha}^{-1}\right)$ was obtained in BR6976-2B-11-1 followed by BRRI dhan43 (1.64 $t$ ha-1) at Kushtia. BR6848-3B-12 showed yield advantage of $1.0 \mathrm{t} \mathrm{ha}^{-1}$ over the check variety BRRI dhan 43 with similar growth duration (104 day). AMMI stability value, yield stability index and GGE Bi-plot model indicated that BR6855-3B-12 is the most adaptable, suitable and stable genotype for broadcast Aus rice across the locations, and finally it is released in 2017 as BRRI dhan83 for broadcast Aus season.
\end{abstract}

Key words: AMMI, broadcast Aus, G $\times E$ interaction, GGE Bi-plot, grain yield, sterility, panicle, phenotypic acceptability

\section{INTRODUCTION}

Rice is the staple food crop in Bangladesh and occupies about $80 \%$ of the country's total cropped area (BRRI, 2019). The total area of the country is 14.86 million ha $(147,570$ sq. $\mathrm{km})$ (Shelley et al., 2016) and the cultivable area is 8.57 million ha (Kabir et al., 2015). Rice is cultivating nearly in $11.42 \mathrm{~m}$ ha (Karmakar and Ali, 2019; BBS, 2018) of which Aus, Aman and Boro rice are covered 9.3, 48.9 and $41.8 \%$, respectively (BRRI, 2019; BBS, 2019). There are three rice-growing seasons in Bangladesh namely Aus, Aman, and Boro. Aus rice is important for environments as it is less water requiring cultivated in pre-monsoon upland rice-growing season under rainfed environments in Bangladesh. Broadcast Aus rice is established through direct broadcasting the seeds in April after the pre-monsoon shower and harvested at July to August (Shelley et al., 2016) but it is practically

${ }^{1}$ Adaptive Research, ${ }^{2}$ Agricultural Statistics, ${ }^{3}$ Plant Physiology, and ${ }^{5}$ Biotechnology Division, Bangladesh Rice Research Institute, Gazipur, Bangladesh. "Khulna University, Khulna, Bangladesh. *Corresponding author's email: biswajitbrri@gmail.com 
harmonized with the climatic season hot summer (Rahman et al., 2018). There are two types of Aus rice such as broadcast/direct seeded Aus also known as upland Aus and partially irrigated Aus or transplanted Aus (TPR-Aus) in Bangladesh. Also transplanting cost is one of the major resource-consuming activities and it could be reduced through cultivating direct-seeded rice (DSR-Aus). Aus rice occupies about $12.53 \%$ of total cultivable area from where modern varieties cover $10.67 \%$ and local varieties cover $1.86 \%$. The present status of total area and production of Aus rice is 1.08 million ha and 2.71 million MT (BBS, 2018).

Puddling soil in repeated manner for transplant rice adversely affects its fertility properties along with declining the subsurface absorptivity (Sharma et al., 2003). This may cause destruction of soil mass and formation of hard aggregates underneath the superficial layer (Gathala et al., 2011). Consequentially, it may affect deleteriously the production of other rotating crops rather than rice (Gopal et al., 2010). Direct seeded broadcast rice would be an attractive alternative on the face of global water scarcity and escalating labour rates in future. In these points of view, direct seeded broadcast rice received much attention in many countries like Australia, America, Europe, Philippines, and Malaysia etc. because of its low input demand (Farooq et al., 2011). Considering that lack of high yielding good quality broadcast rice variety is one of the major constraints. Rice cultivation in Aus season is somewhat decreasing while it is increasing in Boro season, but it is not good for sustainable agriculture. Drought is one of the major abiotic constraints for rice grown under rainfed conditions in Bangladesh and causes a substantial reduction in yield (Shelley et al., 2016). Rice cultivation in Boro season (Dry season) will be a great challenge in future due to the falling down of underground water level in different areas of Bangladesh. Due to global warming, manipulation of evapotranspiration takes place in soil, greenhouse gas emission and other adverse effects pertinent to this are motivating broadcast seeding of rice (Monaco et al., 2016). Aus rice could suffer from drought any time from the seedling to reproductive stages, as the crop is direct-seeded and grown under rainfed upland conditions (Biswas, 2014). However, the traditional Aus varieties have some tolerance to drought and can overcome drought if some rain occurs in June. The yield potential of these rice varieties is very low. The improvement in the yield potential of upland rice may increase production and reduce its cost (Hossain et al., 2013). We have to give more emphasis on the Aus (Pre-wet season rice) and Aman (Wet season rice) based cropping pattern because of uncertainty of water availability for Boro cultivation. Although we have limited scope of horizontal expansion for rice cultivation but still we have some areas in Aus season to explore for rice cultivation. Many fields in our country remain fallow in Aus season which could be used for rice cultivation and it is now very much essential for our sustainable food security. Moreover, rice cultivation in Aus season is also environment-friendly because of its use of rain water without extracting undergroud water. But it is comparatively complex than the other seasons due to unfavourable climatic condition which favours the insect attack and disease incidence. Dry direct seeding of rice is profitable if sufficient weed control approaches are maintained (Rao et al., 2007). Akhgari and Kaviani (2011) reported that DSR can help rice farming communities bring down the labour cost but the only challenge is the weed pressure. With the short duration of growth and high yielding properties of Aus varieties and new herbicides controlling weeds to a large extent has made the transformation of seeding methods from transplanting to broadcast technically viable (Mortimer et al., 2008).

DSR could be a potential substitute for transplanted rice, if weeds are well managed 
(Johnkutty, 2002). Mann (2007) in Pakistan also obtained rice yield of 3.70 ton/ha in a weed free direct seeded rice trial. Similarly, there are many literatures and studies that mention potential of direct seeded rice (Manjunatha et al., 2009 and Sanusan et al., 2010). On the other hand, we do not have potential good broadcast Aus variety with higher yield and shorter growth duration. Sometimes farmers do not show interest to cultivate rice in Aus season, especially broadcast Aus as they feel that it may not be cost effective for them. Despite controversies, if properly managed and developed high yielding varieties, comparable yield may be obtained from direct seeded broadcast rice compared with transplanting rice (Farooq et al., 2011). That is why, we need potential broadcast Aus variety characterised by higher yield, shorter growth duration, good grain quality and also drought tolerent, which are the main criteria for our farmers' attraction to cultivate rice. Therefore, some promising rice genotypes were evaluated along with existing broadcast Aus variety BRRI dhan 43 as check in eight different locations of Bangladesh. Instability is the result of cultivars response in different environments which usually indicates a high interaction between genetic and environmental factors (Lone et al., 2009). Grain yield depends on genotype, environment and management practices and their interaction with each other (Messina et al., 2009). Under the same management conditions, variation in grain yield is principally explained by the effects of genotype and environment (Dingkuhn et al., 2006). The development of rice and other crops is affected by effects of the environment $(\mathrm{E})$, genotype (G) and their interaction (GE) (Mattos et al., 2013). Several statistical methods were used separately to evaluate genotypes and environments of different crops of multilocation trials and GEI data (Malosetti et al., 2013). There are two multivariate analysis such as Additive main effect and multiplicative interaction (AMMI) model and genotype plus genotype by environment interaction (GGE) biplot analysis has been used in this study. These two statistical methods (AMMI and GGEBiplot) have wider importance for agricultural researchers because they affect to any two-way data matrices (Farhad et al., 2017; Crossa, 1990). AMMI analysis can also be used to find out the stability of the genotypes across locations using the PCA (principal component axis) scores and AMMI stability value (Sandhu et al., 2019; Purchase, 1997). Research on adaptability of the Aus rice varieties would help farmers to cultivate right varieties in right environments as well as the policy makers to formulate decision in this regard. The major objectives of the present study were to assess the stability and yield performance of promising broadcast Aus rice genotypes evaluated in multi-environmental conditions and to discover stable high yielding variety(s) for possible release using various statistical tools.

\section{MATERIALS AND METHODS}

Four advanced lines BR6855-3B-12 (G1), BR6855-3B-13 (G2), BR6848-3B-12 (G3) and BR6976-2B-11-1 (G4) along with BRRI dhan43 (G5) as check were tested in Gazipur (E1), Kapasia (E2), Noakhali sadar (E3), Feni (E4), Sylhet (E5), Faridpur (E6), Magura sadar (E7) and Kushtia (E8) during B. Aus 2014. The experiment was conducted in RCB design with three replications. The unit plot size for each entry was $15 \mathrm{~m}^{2}(3 \mathrm{~m} \times 5 \mathrm{~m})$. The time of seed sowing in main field at different locations was not same and the dates were within 15-30 April 2014. Direct seeding in line was done with $25 \mathrm{~cm}$ row spacing. Fertilizers urea, triple super phosphate, Muriate of potash, gypsum and zinc sulfate were applied @ 60, 10, 40, 10 and $4 \mathrm{~kg} \mathrm{~N}, \mathrm{P}, \mathrm{K}, \mathrm{S}$ and $\mathrm{Zn} \mathrm{ha-1}$, respectively. All the fertilizers except urea were applied as basal and urea was applied in three equal splits at 20, 35 and 45 days after seeding 
(DAS). Standard and uniform crop management practices were followed in all the locations. Appropriate measures were taken to control insect but diseases were not controlled to identify susceptibility and tolerance level of the genotypes.

Date of seeding, transplanting, flowering and maturity, plant population $\mathrm{m}^{-2}$, phenotypic acceptance at vegetative and ripening stage, plant height, lodging tolerance, yield and yield components, disease and insect incidence were recorded. Plant population (stand) $\mathrm{m}^{-2}$ was counted at 30 days after seeding (DAS). Feedback from farmers and extension personnel were also recorded. For yield estimation, $10 \mathrm{~m}^{2}$ sample area from each plot was harvested at maturity and grain yields were adjusted to $14 \%$ moisture content. Data were analyzed using the statistical software CropStat7.2.

A combined analysis of variance was performed treating genotype as fixed effect and environment as random effect. The most recent statistical method is the AMMI (Additive Main Effect and Multiplicative Interaction) described by (Zobel et al., 1988) was used to investigate the main effects ( $G$ and $E$ ) and $G \times E$ interactions for grain yield of multi-environment data which includes analysis of variance and principal component analysis. A formula of AMMI stability value (ASV) developed by Purchase et al., (2000) based on the AMMI model's IPC1 and IPC2 scores for each genotype was used to find the stable genotype:

$$
A S V=\sqrt{\frac{S S P C 1}{S S P C 2}(P C 1)^{2}+(P C 2)^{2}}
$$

To integrate both yield performance and stability in a single index namely yield stability index (YSI) statistic (Farshadfar et al., 2011) was applied for selecting high-yielding and stable genotypes. YSI was calculated based on the rank of mean yield of genotype (RY) and rank of ASV (RASV) in a single criterion (YSI) as:

\section{$\mathrm{YSI}=\mathrm{RASV}+\mathrm{RY}$}

Ranks were assigned for mean yield and stability parameter, so that the genotype with the highest yield and the lowest estimated value for each statistic given a rank of 1 (Farshadfar et al., 2011; Roostaei et al., 2014). The genotypes with the lowest ASV value would be more stable. Also GGEbiplot is used to interpret the GE interaction of grain yield of multi-environment trial data (Yan, 2002; Yan et al., 2000). GGEbiplot analysis is a visualization method which graphically displays a GE interaction in two-way table for megaenvironment analysis (e.g., which-won where pattern) that means specific genotypes can be recommended to specific mega-environments; the mean performance and stability (genotype evaluation) and environmental evaluation.

\section{RESULTS AND DISCUSSION}

The interaction effect of location and genotype for grain yield, growth duration, plant height, panicles per unit area, 1000-grain weight, sterility, grains panicle ${ }^{-1}$ and plant population $\mathrm{m}^{-2}$ at 30 DAS (days after seeding) were highly significant at the 0.01 level. The individual effects of genotypes and locations on different parameters were also highly significant at 0.01 levels. As interaction effect for all parameters are significant, the individual effect of genotypes or location is not important for discussion. However, tables 1 and 2 help to have an overall idea about the performance of lines. Grain yield of the tested genotypes varied significantly in different locations due to environmental effect and the tested entries were also varied within the locations (Table 3 ).

\section{Yield stability index (Ysi)}

The rank of ASV and mean grain yield are incorporated in a single stability index namely yield stability index (YSI). YSI allows the simultaneous selection for yield and stability performance; on this basis genotypes with the 
least YSI represent stable genotypes with the high performance (Farshadfar et al., 2011). YSI values indicated that BR6855-3B-12 and BR6855-3B-13 genotype with YSI=3 were high-yielding and stable, in contrast BRRI dhan43 (ck), BR6976-2B-11-1 and BR6848-3B-12 with the highest values $(9,8$ and 7 respectively) were identified as unstable genotypes based on YSI (Table 1). Table 2 shows that yield had positive correlation with yield components like plant height, panicle $\mathrm{m}-$ 2, 1000-grain weight, grains panicle but it had negative correlation with the spikelet sterility of rice genotypes. This finding is in close agreement with the findings of Ndebeh $e t$ al., 2018.

Table 1. AMMI stability value (ASV) and mean performance for grain yield $\left(\mathrm{t} \mathbf{h a}^{-1}\right)$ of the rice genotypes grown at eight environments in Bangladesh.

\begin{tabular}{lllcccc}
\hline Genotype code & \multicolumn{1}{c}{ Genotype } & ASV & YSI & rASV & rYSI & Grain yield $\left(\mathrm{t} \mathrm{ha} \mathrm{a}^{-1}\right)$ \\
\hline G3 & BR6855-3B-12 & 0.282 & 3 & 2 & 1 & 3.64 \\
G2 & BR6855-3B-13 & 0.085 & 3 & 1 & 2 & 3.40 \\
G1 & BR6848-3B-12 & 0.720 & 7 & 4 & 3 & 3.21 \\
G4 & BR6976-2B-11-1 & 0.715 & 8 & 3 & 5 & 2.63 \\
G5 & BRRI dhan43 (ck) & 0.970 & 9 & 5 & 4 & 2.68 \\
\hline
\end{tabular}

Table 2. Correlation coefficient analysis of yield and yield components of the rice genotypes.

\begin{tabular}{lccccccc}
\hline & GY & GD & PHT & PPM & TGW & STER & GPP \\
\hline GY & 1 & & & & & & \\
GD & 0.07 & 1 & & & & & \\
PHT & $0.70^{* * *}$ & 0.04 & 1 & & & \\
PPM & $0.98^{* * *}$ & 0.06 & $0.82^{* * *}$ & 1 & & \\
TGW & $0.54^{* *}$ & $0.87^{* * *}$ & $0.40^{*}$ & $0.55^{* *}$ & 1 & & \\
STER & $-0.95^{* * *}$ & 0.19 & $-0.81^{* * *}$ & $-0.97^{* * *}$ & -0.31 & 1 \\
GPP & $0.99^{* * *}$ & 0.04 & $0.81^{* * *}$ & $0.99^{* * *}$ & $0.52^{* *}$ & $-0.97^{* * *}$ & 1 \\
\hline
\end{tabular}

*** $=1 \%$ level of significance, ${ }^{* *}=5 \%$ level of significance, GY $=$ Grain yield $\left(t \mathrm{tha}^{-1}\right), \mathrm{GD}=$ Growth duration, PHT= Plant height, $\mathrm{PPM}=$ Panicle per $\mathrm{m}^{2}$, TGW= 1000 grain weight, STER= Sterility $(\%)$, GPP= Grain per panicle.

Table 3. Performance of yield components of the rice genotypes, Broadcast Aus 2014.

\begin{tabular}{|c|c|c|c|c|c|c|c|c|c|c|c|c|c|c|c|}
\hline Gen & Genotype & GY & rGY & GD & rGD & PHT & rPHT & PPM & rPPM & GPP & rGPP & TGW & rTGW & STER & rSTER \\
\hline G1 & $\begin{array}{l}\text { BR6855- } \\
\text { 3B-12 }\end{array}$ & 3.21 & 3 & 109 & 1 & 109 & 2 & 252 & 3 & 70 & 3 & 28.2 & 2 & 28.9 & 3 \\
\hline G2 & $\begin{array}{l}\text { BR6855- } \\
\text { 3B-13 }\end{array}$ & 3.40 & 2 & 108 & 2 & 108 & 3 & 255 & 2 & 71 & 2 & 28.5 & 1 & 27.3 & 4 \\
\hline G3 & $\begin{array}{l}\text { BR6848- } \\
\text { 3B-12 }\end{array}$ & 3.64 & 1 & 104 & 5 & 112 & 1 & 258 & 1 & 75 & 1 & 24.3 & 3 & 24.1 & 5 \\
\hline G4 & $\begin{array}{l}\text { BR6976- } \\
\text { 2B-11-1 }\end{array}$ & 2.63 & 5 & 106 & 3 & 91 & 5 & 241 & 5 & 60 & 5 & 23.3 & 4 & 32.6 & 1 \\
\hline G5 & $\begin{array}{l}\text { BRRI } \\
\text { dhan43 } \\
\text { (ck) }\end{array}$ & 2.68 & 4 & 105 & 4 & 108 & 4 & 245 & 4 & 64 & 4 & 23.0 & 5 & 30.2 & 2 \\
\hline $\mathrm{LSD}_{0.05}$ & & 0.53 & & 2.0 & & 2.5 & & 17.1 & & 7.0 & & 0.6 & & 5.7 & \\
\hline $\mathrm{CV}(\%)$ & & 10.4 & & 1.1 & & 1.5 & & 4.2 & & 6.3 & & 1.3 & & 12.0 & \\
\hline
\end{tabular}

$\mathrm{GY}=$ Grain yield $\left(\mathrm{t} \mathrm{ha} \mathrm{a}^{-1}\right), \mathrm{GD}=$ Growth duration, $\mathrm{PHT}=$ Plant height, $\mathrm{PPM}=$ Panicle per $\mathrm{m}^{2}$, $\mathrm{TGW}=1000$ grain weight, STER= Sterility (\%), GPP= Grain per panicle, $r=$ rank of (GY, GD, PHT, PPM, GPP, TGW, STER). 


\section{Grain yield}

Grain yield was significantly influenced by genotypes, environment and their interaction (Table 4 and Fig. 1). This result was in conformity with the earlier findings of Babu et al. (2012), Karmakar et al. (2015) and Vanisree et al. (2013). Irrespective of locations and genotypes, the highest mean grain yield (3.64 $\left.\mathrm{t} \mathrm{ha}^{-1}\right)$ was obtained in BR6848-3B-12 and it was almost $1.0 \mathrm{t}^{\mathrm{ha}}-1$ higher than the standard check variety BRRI dhan43 (2.68 $\left.\mathrm{t} \mathrm{ha}^{-1}\right)$. The genotype BR6848-3B-12, BR6855-3B-12 and BR68553B-13 performed better in almost all the locations possibly due to their higher adaptation to different environments. These findings corroborate with the report of Ndebeh et al., 2018. Across the locations, the highest grain yield (4.88 $\left.\mathrm{t} \mathrm{ha}^{-1}\right)$ obtained in BR6848-3B-12 at Sonagazi, Feni that followed by Magura (4.81 $\left.\mathrm{t} \mathrm{ha}^{-1}\right)$. It is might be due to the environments was suitable for obtaining higher yield performances. Grain yield of the genotypes varied from location to location might be due to environmental effect (Karmakar et al., 2015; Sakai et al., 2010). The lowest yield (1.58 $\left.\mathrm{t} \mathrm{ha}^{-1}\right)$ was found in BR6976-2B-11-1 followed by BR6855-3B-13 (2.10 $\left.\mathrm{t} \mathrm{ha}^{-1}\right)$ at Veramara, Kushtia (Table 4). Overall yield performance of the genotypes was good and consistent without some exceptions in Veramara, Kushtia and Madhukhali, Faridpur where the trials were suffered by drought and scarcity of rain water. In respect to yield and growth duration, most of the tested genotypes except BR6976-2B11-1 performed better than the check variety BRRI dhan43.

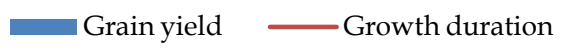

$\mathrm{LSD}_{0.05}$ for $\mathrm{GY}=0.19, \mathrm{LSD}_{0.05}$ for $\mathrm{GD}=1$

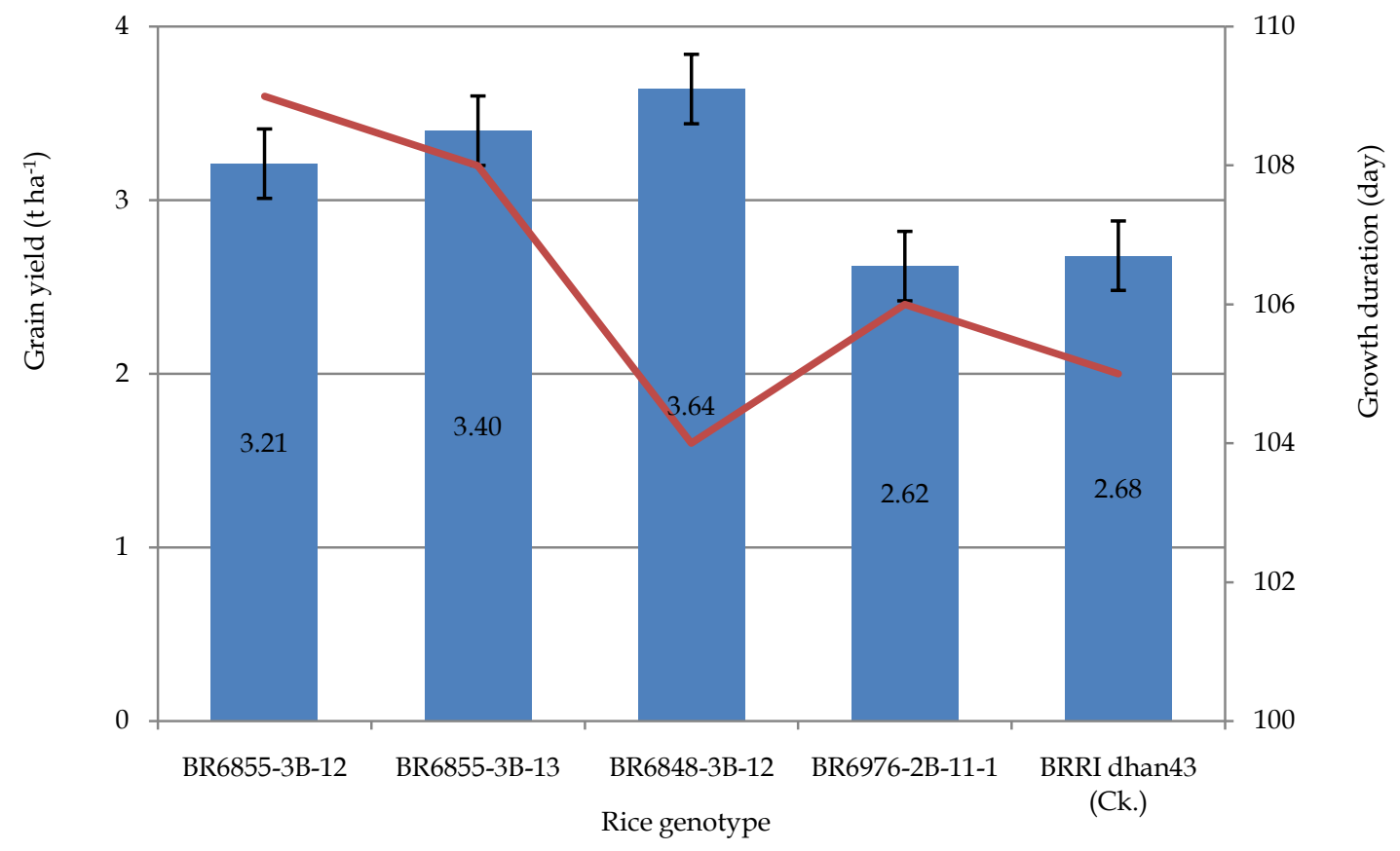

Fig. 1. Mean grain yield and growth duration of genotypes, broadcast Aus 2014. 
Table 4. Interaction effect of genotypes and environments ( $G \times E)$ on grain yield and growth duration of the rice genotypes, Broadcast Aus 2014.

\begin{tabular}{|c|c|c|c|c|c|c|c|c|}
\hline \multirow{2}{*}{$\begin{array}{l}\text { Location } \\
\text { Genotype }\end{array}$} & Gazipur & Gazipur & Noakhali & Feni & Sylhet & Faridpur & Magura & Kushtia \\
\hline & (BRRI) & (Kapasia) & (Sadar) & (Sonagazi) & (Golapganj) & (Madhukhali) & (Sadar) & (Veramara) \\
\hline \multicolumn{9}{|c|}{ Grain yield ( $\left.h^{-1}\right)$} \\
\hline BR6855-3B-12 & 2.84 & 2.90 & 3.32 & 4.29 & 3.31 & 2.74 & 4.08 & 2.18 \\
\hline BR6855-3B-13 & 3.05 & 3.32 & 3.46 & 4.31 & 3.47 & 2.90 & 4.56 & 2.10 \\
\hline BR6848-3B-12 & 3.37 & 3.60 & 3.34 & 4.88 & 3.94 & 2.96 & 4.81 & 2.26 \\
\hline BR6976-2B-11-1 & 2.23 & 2.65 & 2.68 & 3.83 & 2.25 & 2.45 & 3.34 & 1.58 \\
\hline $\begin{array}{l}\text { BRRI dhan43 } \\
\text { (ck) }\end{array}$ & 2.68 & 2.57 & 2.78 & 3.22 & 3.11 & 2.34 & 3.10 & 1.64 \\
\hline F-test & $* *$ & $* *$ & $* *$ & $* *$ & $* *$ & $* *$ & $* *$ & $* *$ \\
\hline $\mathrm{LSD}_{0.05}$ & \multicolumn{8}{|c|}{0.53} \\
\hline \multicolumn{9}{|c|}{ Growth duration (day) } \\
\hline BR6855-3B-12 & 108 & 109 & 112 & 112 & 106 & 107 & 108 & 107 \\
\hline BR6855-3B-13 & 107 & 109 & 108 & 111 & 106 & 107 & 109 & 107 \\
\hline BR6848-3B-12 & 104 & 106 & 105 & 107 & 101 & 103 & 106 & 102 \\
\hline BR6976-2B-11-1 & 105 & 107 & 108 & 107 & 103 & 106 & 107 & 106 \\
\hline $\begin{array}{l}\text { BRRI dhan } 43 \\
\text { (ck) }\end{array}$ & 103 & 105 & 106 & 108 & 102 & 105 & 107 & 106 \\
\hline F-test & $* *$ & $* *$ & $* *$ & $* *$ & $* *$ & $* *$ & $* *$ & $* *$ \\
\hline $\mathrm{LSD}_{0.05}$ & & & & & 2 & & & \\
\hline
\end{tabular}

The GGE biplot explained $88.23 \%$ and $8.75 \%$ accounted $96.98 \%$ of the total variation of the environments for grain yield. GGE biplot showed three distinct clusters in one containing four locations Kapasia Gazipur (E2); Noakhali (E3); Kushtia (E8) and Faridpur (E6), and the second containing Gazipur sadar (E1) and Sylhet (E5), third one containing Feni (E4); and Magura (E7) (Fig. 2.a). Among experimental location first cluster of environments are more stable environments and Kapasia Gazipur (E2) is the ideal location among them for testing genotypes based on GGEBiplot analysis. The closest association was observed between the environments Noakhali (E3), and Kushtia (E8); and Kapasia Gazipur (E2) and Faridpur (E6). To evaluate the genotypes according to ranking with reference to the mean value of grain yield stability across environments, the AEC method can be used in the GGE biplot graph (Fig. 2.b). BR6848-3B-12 (G3) recorded the highest average grain yield. BR6848-3B-12 (G3), BR6855-3B-13 (G2), and BR6855-3B-12 (G1) were the most stable genotypes with aboveaverage yields. Thus, the BR6848-3B-12 (G3) was the most ideal genotype with the highest mean yield and stability among the tested genotypes. Also BR6976-2B-11-1 (G4) and BRRI dhan43 (ck) (G5) were unstable and low yielder genotypes. The biplot showed one sector containing all the test environments and BR6848-3B-12 (G3), BR6855-3B-13 (G2) and BR6855-3B-12 (G1) were the winning genotypes and Kapasia Gazipur (E2), Noakhali (E3), Noakhali (E6) and Kushtia (E8) were the best for tested locations of these three genotypes (Fig. 2.c). 

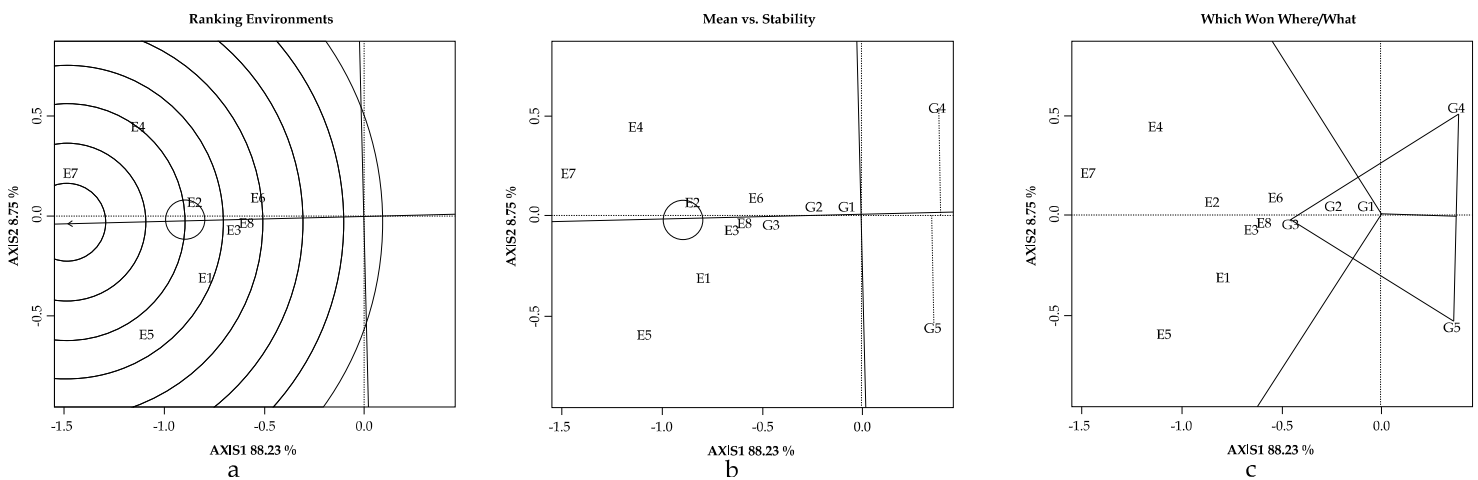

Fig. 2. GGE Biplot for (a) ranking environments (b) mean vs stability (c) which won where for broadcast Aus 2014.

Breeding View software (Breeding Management System v3.9) (https:// integratedbreeding.net/) a version of GenStat software was used for analyzing grain yield data for characterizing environments and interactions to the genotypes performance through Finlay-Wilkinson regression (Malosetti, et al., 2013). Based on grain yield, two environments (Feni and Magura) showed high performing environment having median yield $>4.0 \quad \mathrm{t} \mathrm{ha} \mathrm{h}^{-1}$ with characteristics with higher variances. Kushtia performed poor showing median yield about $2 \mathrm{t} \mathrm{ha}^{-1}$ but the rest five environments perform moderately median yield ranged from 2.75 to $3.25 \mathrm{t} \mathrm{ha}^{-1}$ ) (Fig. 3). Correlation between environments showed all eight environments have strong positive correlations (Fig. 4) indicating any better genotypes selected from this study could be recommended for similar environments. Finlay-Wilkinson regression represents the yield performances of the genotypes across environments in visual mode (Fig. 5). Among the tested four genotypes, three (BR6848-3B-12, BR6848-3B-13 and BR6848-3B-12) performed superiorly compared to BR6976-2B-11-1 and check BRRI dhan43. Among the three best performing genotype, BR6848-3B-12 was found superior for all three categories of environments (poor, moderate and high performing environment). Moreover, the superior genotype (BR6848-3B12) out yielded in the high performing environments indicating it has potentiality to perform superiorly in all high performing environments as well as performing better in moderate and poor environments (Fig. 5).

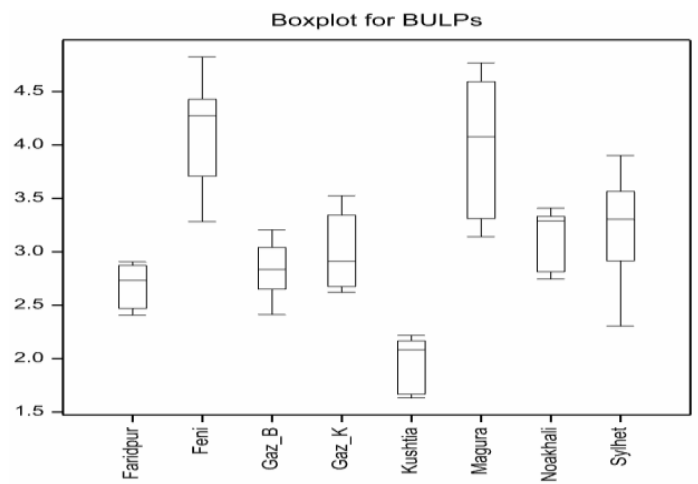

Fig. 3. Boxplot for grain yield of the rice genotypes representing performance of the environments based on yield of B. Aus rice (Gaz_B = BRRI, Gazipur and Gaz_K=Kapasia, Gazipur).

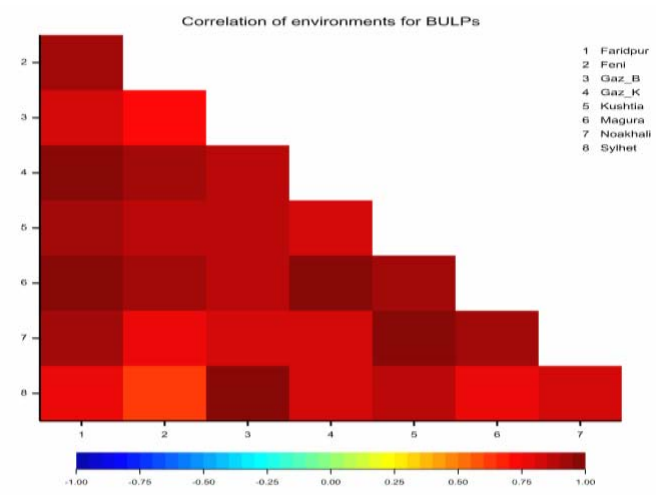

Fig. 4. Correlation between environments based on yield performances of the rice genotypes (Gaz_B = BRRI, Gazipur and Gaz_K=Kapasia, Gazipur). 


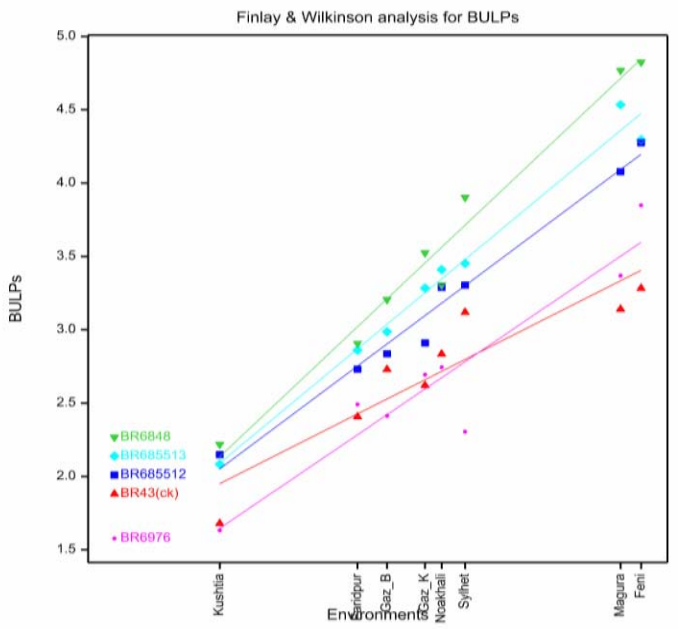

Fig. 5. Finlay-Wilkinson Regression for grain yield of the rice genotypes representing performances and interactions between genotype (BR6848 = BR6848-3B12, BR685513 = BR6858-3B-13, BR685512 = BR68583B-12, BR43 (ck) = BRRI dhan43 and BR6979= BR6979-2B-11-1) and environments (Gaz_B = BRRI, Gazipur and Gaz_K= Kapasia, Gazipur).

\section{Growth Duration}

Growth duration of the genotypes widely and significantly varied across the genotypes and locations (Table 4). These findings are in alignment with Karmakar et al. (2015) and Sakai et al. (2010). Mean growth duration of the tested genotypes ranged from 104 to 109 days whereas it was 106 days for the check variety BRRI dhan43 (Table 4). The highest yielder, BR6848-3B-12 matured within the shortest period of time (104 days) which was two days earlier than that of check the variety BRRI dhan43 (106 days). The growth duration of $2^{\text {nd }}$ (BR6855-3B-13) and $3^{\text {rd }}$ (BR6855-3B-12) highest yielder were 108 and 109 days, respectively which were little bit longer (1-3 days) than BRRI dhan43.

\section{Plant population}

Plant population (stand) counted at 30 DAS was significantly affected by genotypes, locations and their interactions (Table 5). Plant population per unit area (per square meter) varied from 169 to 215 for the tested advanced lines and it was 165 for the check variety BRRI dhan43 (Table 5). Across the locations, the highest plant population $\mathrm{m}^{-2}$ (250) was found in BR6848-3B-12 at Magura and the lowest (130) was in BRRI dhan43 at Veramara, Kushtia. Depending on rain water, rice cultivation in Aus season by broadcasting is comparatively difficult. Especially seed germination is hampered due to unavailability of soil moisture which might be affected the homogenesity of this experiment for all locations.

\section{Plant height}

Genotypes by environments interaction had significant effect on plant height of the genotypes (Table 5). Across the locations, the longest plant $(113 \mathrm{~cm})$ was found in the genotype BR6848-3B-12 at Noakhali and Feni that was followed by BRRI dhan43 (112 $\mathrm{cm})$ at Feni. Plant height of BR6976-2B-11-1 was horter at alomost all the locations. It might be due to its genetical characteristcs. Plent height of the genotypes ranged from 85 to $113 \mathrm{~cm}$ across the locations. Plant height of the highest yielder was significantly taller than all other the geontypes including check variety BRRI dhan43. However, plant height of $2^{\text {nd }}$ and $3^{\text {rd }}$ yielder were was similar to that of the check variety. The plant height of the tested genotypes were also very much expective and similar to that of check variety which might be a promising one for Broadcast Aus season in Bangladesh. 
Table 5. Interaction effects of genotypes and environments on plant stand $\mathrm{m}^{-2}$ at seedling stage (30 DAS) and plant height at maturity stage.

\begin{tabular}{|c|c|c|c|c|c|c|c|c|c|}
\hline Genotype & $\begin{array}{l}\text { Gazipur } \\
\text { (BRRI) }\end{array}$ & $\begin{array}{l}\text { Gazipur } \\
\text { (Kapasia) }\end{array}$ & $\begin{array}{c}\text { Noakhali } \\
\text { (Sadar) }\end{array}$ & $\begin{array}{c}\text { Feni } \\
\text { (Sonagazi) }\end{array}$ & $\begin{array}{c}\text { Sylhet } \\
\text { (Golapganj) }\end{array}$ & $\begin{array}{c}\text { Faridpur } \\
\text { (Madhukhali) }\end{array}$ & $\begin{array}{l}\text { Magura } \\
\text { (Sadar) }\end{array}$ & $\begin{array}{c}\text { Kushtia } \\
\text { (Veramara) }\end{array}$ & Mean \\
\hline \multicolumn{10}{|c|}{ Plant stand $m^{-2}$} \\
\hline BR6855-3B-12 & 206 & 210 & 216 & 231 & 223 & 189 & 228 & 133 & 205 \\
\hline BR6855-3B-13 & 202 & 208 & 211 & 236 & 225 & 232 & 231 & 151 & 212 \\
\hline BR6848-3B-12 & 204 & 197 & 227 & 244 & 238 & 232 & 250 & 146 & 217 \\
\hline BR6976-2B-11-1 & 146 & 162 & 168 & 224 & 192 & 215 & 231 & 136 & 184 \\
\hline BRRI dhan43 (ck) & 176 & 180 & 183 & 212 & 207 & 152 & 201 & 130 & 180 \\
\hline F-test & $* *$ & $* *$ & $* *$ & $* *$ & $* *$ & $* *$ & $* *$ & $* *$ & $* *$ \\
\hline $\mathrm{LSD}_{0.05}$ & & & 33 & & & & & & 12 \\
\hline \multicolumn{10}{|c|}{ Plant height $(\mathrm{cm})$} \\
\hline BR6855-3B-12 & 109 & 111 & 110 & 111 & 108 & 107 & 110 & 105 & 109 \\
\hline BR6855-3B-13 & 108 & 111 & 109 & 111 & 106 & 107 & 107 & 106 & 108 \\
\hline BR6848-3B-12 & 112 & 112 & 113 & 113 & 111 & 111 & 112 & 111 & 112 \\
\hline BR6976-2B-11-1 & 92 & 89 & 93 & 96 & 86 & 90 & 95 & 85 & 91 \\
\hline BRRI dhan43 (ck) & 109 & 107 & 110 & 112 & 106 & 106 & 109 & 104 & 108 \\
\hline F-test & $* *$ & $* *$ & $* *$ & $* *$ & $* *$ & $* *$ & $* *$ & $* *$ & $* *$ \\
\hline $\mathrm{LSD}_{0.05}$ & & & 3 & & & & & & 1 \\
\hline
\end{tabular}

\section{Yield components}

Yield components like panicle $\mathrm{m}^{-2}$, 1000-grain weight (TGW), grains panicle ${ }^{-1}$ and spikelet sterility were significantly affected by the genotypes, environments and their interactions (Table 6). Panicles production per unit area $\left(\mathrm{m}^{2}\right)$ varied from 206 to 281 for different genotypes including check variety across the locations. This finding was in conformity with the findings of Ndebeh et al. (2018). The highest number of panicles $\mathrm{m}^{-2}$ (281) obtained in BR6855-3B-13 at Sonagazi, Feni that was followed by BR6855-3B-12 (280) and BR68483B-12 (279). The lowest number (206) of panicles $\mathrm{m}^{-2}$ was recorded in BR6976-2B-11-1 at Veramara, Kushtia followed by BRRI dhan 43 (212). In general, panicles production per unit area in Veramara, Kushtia was lower for all the genotypes compared to the other locations as the crop of Kushtia severely affected by drought stress that reflected also in grain yield.

Grain weight of the tested genotypes significantly affected by the interaction of genotypes and environments (Table 6). Lack et al. (2012) also stated that there was a significant difference between cultivars regarding grain weight. Across the locations, the highest TGW (28.8 g) was found in BR6855-3B-13 at Magura followed by Feni $(28.7 \mathrm{~g})$. The lowest 1000grain weight $(22.7 \mathrm{~g})$ was obtained in BRRI dhan43 at Veramara, Kushtia followed by Madhukhali, Faridpur and Gazipur (22.8 g). Grain weight of the tested genotypes including the check variety was lower compared to the other locations. It was happened might be due to drought effect at Veramara, Kushtia as the crop suffered severe drought stress at that location. In general, grain weight of all the genotypes was higher than the check variety BRRI dhan43. Mean TGW of the highest yielder was $24.3 \mathrm{~g}$ which was much lower than that of $2^{\text {nd }}$ and $3^{\text {rd }}$ highest yielder $(28.7 \mathrm{~g})$ and it indicates the fineness and slenderness of the advanced line BR6848-3B-12. Although grain weight is one of the important genetic characteristic, however it was remarkedly influenced by the locations might be due to environmental effect.

Grains production per panicle of the genotypes was substantially variable across the 
genotypes which were affected by genotypes, environments and their interaction (Rai and Kushwaha, 2008). Grains panicle ${ }^{-1}$ ranged from 52 to 85 across the locations. The highest yielder BR6848-3B-12 produced the highest number of grains (85) at Feni while the lowest yielder BR6976-2B-11-1 produced the lowest number of grains panicle (52) at Kushtia and Gazipur (Table 6). Grains panicle-1 was in generally, lower in trend as the crop was grown under rainfed condition, and the crop suffered different stresses especially water stress in some locations.
Spikelet sterility varied significantly among the genotypes, environments and their interaction (Table 6). Sterility was ranged from 21 to $42 \%$ across the locations (Table 6). Genotypes had strong significant effect spikelet sterility (Karmakar et al., 2015) The highest sterility $(42 \%)$ observed in the lowest yielder BR6976-2B-11-1 at Veramara, Kushtia that was followed by BRRI dhan $43(40 \%)$. Spiklets sterility negtively correlated with grain yield and it affected higher yield of BR6976-2B-11-1 and BRRI dhan43. Sterilty increased with increasing drought stress across the locations.

Table 6. Interaction effect of genotypes and environments on yield components of the rice genotypes.

\begin{tabular}{|c|c|c|c|c|c|c|c|c|c|}
\hline Genotype & $\begin{array}{c}\text { Gazipur } \\
\text { (BRRI) }\end{array}$ & $\begin{array}{l}\text { Gazipur } \\
\text { (Kapasia) }\end{array}$ & $\begin{array}{c}\text { Noakhali } \\
\text { (Sadar) }\end{array}$ & $\begin{array}{c}\text { Feni } \\
\text { (Sonagazi) }\end{array}$ & $\begin{array}{c}\text { Sylhet } \\
\text { (Golapganj) }\end{array}$ & $\begin{array}{c}\text { Faridpur } \\
\text { (Madhukhali) }\end{array}$ & $\begin{array}{l}\text { Magura } \\
\text { (Sadar) }\end{array}$ & $\begin{array}{c}\text { Kushtia } \\
\text { (Veramara) }\end{array}$ & Mean \\
\hline \multicolumn{10}{|c|}{ Panicles $m^{-2}$ (no.) } \\
\hline BR6855-3B-12 & 243 & 247 & 259 & 280 & 264 & 244 & 261 & 215 & 252 \\
\hline BR6855-3B-13 & 245 & 249 & 260 & 281 & 263 & 253 & 272 & 218 & 255 \\
\hline BR6848-3B-12 & 254 & 256 & 253 & 279 & 265 & 261 & 268 & 230 & 258 \\
\hline BR6976-2B-11-1 & 237 & 241 & 245 & 262 & 247 & 228 & 260 & 206 & 241 \\
\hline BRRI dhan43 (ck) & 245 & 242 & 255 & 260 & 251 & 231 & 267 & 212 & 245 \\
\hline F-test & $* *$ & $* *$ & $* *$ & $* *$ & $* *$ & $* *$ & $* *$ & $* *$ & $* *$ \\
\hline $\mathrm{LSD}_{0.05}$ & & & 17 & & & & & & 6 \\
\hline \multicolumn{10}{|c|}{1000 -grain weight $(g)$} \\
\hline BR6855-3B-12 & 28.2 & 28.4 & 28.1 & 28.6 & 28.4 & 28.1 & 28.4 & 27.5 & 28.2 \\
\hline BR6855-3B-13 & 28.3 & 28.5 & 28.6 & 28.7 & 28.5 & 28.6 & 28.8 & 27.6 & 28.5 \\
\hline BR6848-3B-12 & 24.3 & 24.6 & 24.4 & 24.5 & 24.0 & 23.9 & 24.5 & 23.8 & 24.3 \\
\hline BR6976-2B-11-1 & 23.1 & 23.2 & 23.0 & 23.5 & 23.3 & 23.1 & 23.6 & 23.0 & 23.2 \\
\hline BRRI dhan43 (ck) & 22.8 & 23.1 & 23.0 & 23.3 & 23.1 & 22.8 & 23.4 & 22.7 & 23.0 \\
\hline F-test & $* *$ & $* *$ & $* *$ & $* *$ & $* *$ & $* *$ & $* *$ & $* *$ & $* *$ \\
\hline $\mathrm{LSD}_{0.05}$ & & & 0.6 & & & & & & 0.2 \\
\hline \multicolumn{10}{|c|}{ Grains panicle $^{-1}$ (no.) } \\
\hline BR6855-3B-12 & 65 & 68 & 71 & 80 & 71 & 68 & 77 & 56 & 70 \\
\hline BR6855-3B-13 & 70 & 72 & 68 & 81 & 73 & 69 & 80 & 57 & 71 \\
\hline BR6848-3B-12 & 69 & 71 & 72 & 85 & 75 & 81 & 82 & 66 & 75 \\
\hline BR6976-2B-11-1 & 52 & 55 & 65 & 68 & 66 & 60 & 61 & 52 & 60 \\
\hline BRRI dhan43 (ck) & 63 & 61 & 64 & 69 & 66 & 62 & 67 & 58 & 64 \\
\hline F-test & $* *$ & $* *$ & $* *$ & $* *$ & $* *$ & $* *$ & $* *$ & $* *$ & $* *$ \\
\hline $\mathrm{LSD}_{0.05}$ & & & 7 & & & & & & 3 \\
\hline \multicolumn{10}{|c|}{ Sterility (\%) } \\
\hline BR6855-3B-12 & 31 & 28 & 27 & 24 & 27 & 33 & 26 & 35 & 29 \\
\hline BR6855-3B-13 & 26 & 23 & 27 & 26 & 24 & 32 & 27 & 34 & 27 \\
\hline BR6848-3B-12 & 25 & 25 & 24 & 21 & 23 & 24 & 22 & 30 & 24 \\
\hline BR6976-2B-11-1 & 36 & 32 & 30 & 27 & 33 & 32 & 29 & 42 & 33 \\
\hline BRRI dhan43 (ck) & 29 & 31 & 28 & 25 & 28 & 35 & 26 & 40 & 30 \\
\hline F-test & $* *$ & $* *$ & $* *$ & $* *$ & $* *$ & $* *$ & $* *$ & $* *$ & $* *$ \\
\hline $\mathrm{LSD}_{0.05}$ & & & 5 & & & & & & 2 \\
\hline
\end{tabular}




\section{Insect infestation}

Proper control measures were taken as and when necessary so that the trials were almost free from insect's damage. However, stem borer (3-10\%) and rice bug infestations (5-15\%) were common in most of the locations.

\section{Disease infection}

Most of the genotypes including check variety BRRI dhan43 were found to be disease free in most of the locations except Gazipur and Sylhet where almost all the entries were affected by some diseases. BRRI dhan 43 was less infected by sheath blight (10-15\%) and BR6855-3B-13 was affected by sheath rot (20\%). In Sylhet, all the entries were affected by Sheath blight ranged from 5 to $90 \%$ and Brown spot (3-10\%). In Kushtia, brown spot (5-10\%) was found in all entries.

\section{Lodging incidence}

The tested genotypes were lodging tolerant in all locations except at Gazipur and Feni sites. Due to heavy rain and stagnant water, almost all the genotypes including BRRI dhan43 were lodged by $25-60 \%$, however the highest yielder BR6848-3B-12 was found to be less lodged (25\%) at Gazipur site. Moreover, BRRI dhan43 was lodged by $50 \%$ but the tested genotypes showed lodging tolerant at Sonagazi of Feni district.
Feedback of farmers and extension personnel

Most of the farmers and extension personnel preferred BR6848-3B-12 for its higher yield, shorter growth duration and medium bold reddish grain. Some farmers also preferred BR6855-3B-12 and BR6855-3B-13 for their good yield and shorter growth duration.

\section{CONCLUSION}

Among the tested genotypes, BR6848-3B-12 was the most productive and it had about $1.0 \mathrm{t}$ ha $^{-1}$ yield advantage over the check variety BRRI dhan43. All the tested genotypes were found almost disease free in all the locations except Gazipur and Sylhet while BRRI dhan43 was infected by sheath blight disease at BRRI Gazipur and Sylhet. Based on overall performances, yield advantage, grain size, growth duration, farmers preference, pest tolerance and phenotypic acceptance; BR68483B-12 recommended for proposed variety trial and finally the genotype is released as BRRI dhan83 in 2017 for broadcast Aus season. It is concluded that BRRI dhan83 would have good potential to increase yield and area of broadcast Aus throughout the country.

Table 7. Phenotypic acceptance of the rice genotypes.

\begin{tabular}{|c|c|c|c|}
\hline \multirow{2}{*}{ Genotype } & \multirow{2}{*}{ Comments on phenotypic acceptance } & \multicolumn{2}{|c|}{ *PAcp Score } \\
\hline & & Veg. & Mat. \\
\hline BR6855-3B-12 & $\begin{array}{l}\text { Rice plant remains green up to maturity. Flag leafs are erect. Grains are } \\
\text { bold with uniform flowering and maturity. }\end{array}$ & 5 & 7 \\
\hline BR6855-3B-13 & $\begin{array}{l}\text { Uniform flowering and maturity, bold grain. Long panicle with green } \\
\text { and erect flag leaf }\end{array}$ & 5 & 7 \\
\hline BR6848-3B-12 & $\begin{array}{l}\text { Plants remain green up to maturity. Uniform flowering and maturity } \\
\text { with medium bold grain. Panicle long and it remains above flag leaf. } \\
\text { Rice grain turns in golden radish color at maturity stage. }\end{array}$ & 3 & 5 \\
\hline BR6976-2B-11-1 & Irregular flowering and maturity, Plant too short. & 5 & 9 \\
\hline BRRI dhan43 (ck) & Uniform flowering and maturity, Grain medium bold and poor yield. & 5 & 5 \\
\hline
\end{tabular}

*Phenotypic acceptability (PAcp): 1=Excellent, 3=Good, 5=Fair, 7=Poor, 9=Unacceptable (IRRI, 2014). 


\section{REFERENCES}

Akhgari, H and B Kaviani. 2011. Assessment of direct seeded and transplanting methods of rice cultivars in the northern part of Iran. African J. Agri. Res. 6(31):6492-6498.

Babu, V R, K Shreya, K S Dangi, G Usharani and P Nagesh. 2012. Genetic variability studies for qualitative and quantitative traits in popular rice hybrids of India. International J. Scientific and Res. Public. 2(6):2250-3153.

BBS (Bangladesh Bureau of Statistics). 2018. Agriculture statistics of major crops. Statistics and Informatics Division (SID), Bangladesh Bureau of Statistics, Government of the People's Republic of Bangladesh. pp. 21-22.

BBS (Bangladesh Bureau of Statistics). 2019. Agriculture statistics of major crops. Statistics and Informatics Division (SID), Bangladesh Bureau of Statistics, Government of the People's Republic of Bangladesh. pp. 1-25.

Biswas, J K. 2014. Growing Rice Under Stress Environment. A Report from Director General of Bangladesh Rice Research Institute, Published in Daily Star (A leading daily Newspaper), March 15, 2014.

BRRI (Bangladesh Rice Research Institute). 2019. Adhunik Dhaner Chash (Cultivation of Modern Rice), Gazipur, Bangladesh. pp. 5-93.

Crossa, J. 1990. Statistical analysis of multilocation trials. Adv. In Agron. 44: 55-86.

Dingkuhn, M, D Luquet, H Kim, L Tambour and A C Vidal. 2006. Eco meristem, a model of morphogenesis and competition among sinks in rice. Simulating genotype responses to phosphorus deficiency. Functional Plant Biology 33:325-337.

Farhad, M, M Alam, M A Hakim, N Barma, P K Malakar, M A R Mostafa, A Hossain and L I Minju. 2017. AMMI and GGE biplot analysis for yield stability of promising bread wheat genotypes in Bangladesh. Pakistan J. Botany 40: 1049-1056.

Farooq, M, K H M Siddique, H Rehman, T Aziz, D J Lee, and A Wahid. 2011. Rice direct seeding: Experience, Challenges and opportunities. Soil and Tillage Res. 111:87-98.

Farshadfar, E, N Mahamodi and A Yaghotipoor. 2011. AMMI stability value and simultaneous estimation of yield and yield stability in bread wheat (Triticumaestivum L.). Australian J. of Crop Sci. 5 (13):1837-1844.

Gathala, M K, J K Ladha, V Kumar, Y S Saharawat, V Kumar, P K Sharma, S Sharma and H Pathak. 2011. Tillage and crop establishment affects sustainability of South Asian rice-wheat system. Agron. J. 103:961-971.

Gopal, R, R K Jat, R K Malik, V Kumar, M M Alam, M L Jat, M A Mazid, Y S Saharawat, A McDonald and R
Gupta. 2010. Direct Dry Seeded Rice Production Technology and Weed Management in Rice Based Systems. Technical Bulletin. International Maize and Wheat Improvement Center. New Delhi, India, 28pp.

Hossain, M, W M H Jaim, M S Alam and A N M Rahman. 2013. Rice biodiversity in Bangladesh: Adoption, Diffusion and Disappearance of Varieties. Bangladesh Rural Advancement Committee, Research and Evaluation Division, Dhaka, Bangladesh.

IRRI (International Rice Research Institute). 2014. Standard Evaluation System for Rice. International Rice Research Institute, Los Banos, Philippines. pp. 1-57.

John, I, G Mathew and J Mathew. 2002. Comparison between transplanting and direct seeding methods for crop establishment in rice. J. of Tropical Agriculture 40:6566.

Kabir, M S, M U Salam, A Chowdhury, N M F Rahman, K M Iftekharuddaula, M S Rahman, M H Rashid, S S Dipti, A Islam, M A Latif, A K M S Islam, M M Hossain, B Nessa, T H Ansari, M A Ali and J K Biswas. 2015. Rice Vision for Bangladesh: 2050 and Beyond. Bangladesh Rice J. 19(2):1-18.

Karmakar, B, M A Islam, M R Islam, M H R Mukul, MR Biswash, R Barua, A Zahan, S Naher, P Saha, S Parveen and M S I Mamin. 2015. On-farm Evaluation of Rice Genotypes under Drought Prone Rainfed Environments. Sci. Agri. 12(2):72-77.

Karmakar, B, and M A R Sarkar. 2015. Optimizing seedling age of promising rice genotypes in rainfed environment. J. Crop and Weed. 11(Special Issue):149-160.

Karmakar, B and M A Ali. 2019. Production and Preservation of Quality Rice Seed. 1st Edition, Bangladesh Rice Research Institute, Gazipur. pp.136.

Lack, S, N M Marani and M Mombeni. 2012. Effect of planting date on grain yield and yield components of rice cultivars. Adv. Env.Biol. 6:406-13.

Lone, A A, P A Sofi, M Z Warsi and S H Wani. 2009. Stability analysis in maize (Zea mays L.) for anthesis silking interval and grain yield. Maize Genetics Cooperation Newsletter 83:19.

Malosetti, M, J M Raibaut, F A V Eeuwijk. 2013. The statistical analysis of multi-environment data: modeling genotype-by-environment interaction and its genetic basis. Front Physiol.4: 44 .

Manjunatha, M V, B G Reddy and V R Joshi. 2009. Performance of rice (Oryza sativa) under different menthod of establishment in Tungabhadra canal command, Karnataka. Karnataka J. of Agriculture Sci. 22(5):1151-1152.

Mann, R A, S Ahmad, G Hassan and M S Baloch. 2007. Weed management in direct seeded rice crop. Pakistan J. of Weed Sci. Res. 13(3-4): 219-226. 
Mattos, P H C, R A Oliveira, B Filho, J Carlos, D Edelclaiton, and V M A Aloiso. 2013. Evaluation of sugarcane genotypes and production environments in Paraná by GGE biplot and AMMI analysis. Crop Breeding and Applied Biotechnology 13(1):83-90.

Monaco, F, G Sali, M B Hassen, A Facchi, M Romani and G Valè. 2016. Water management options for rice cultivation in a temperate area: a multi-objective model to explore economic and water saving results. Water 8, 336-355.

Mortimer, A M, C R Riches, M Mazid, S Pandey and D E Johnson. 2008. Issues related to direct seeding of rice in rainfed cropping systems in northwest Bangladesh. International Rice Research Institute. Philippines, and Directorate of Experiment Station, G.B. Pant University of Agriculture and Technology, Pantnagar, Uttaranchal, India, $272 \mathrm{p}$.

Messina, C, G Hammer, Z Dong, D Podlich and M Cooper. 2009. Modelling crop improvement in a $\mathrm{G} \times \mathrm{E} \times \mathrm{M}$ framework via gene-trait-phenotype relationships. In: Sadras, VO, Calderini, D. (Eds.), Crop physiology: Applications for Genetic Improvement and Agronomy. Elsevier, Netherlands, pp. 235-265.

Ndebeh, AK1, P Asumanah, J Ndebeh, P G Ndaloma, SJB Lahai, D M Kolleh and J K Ahiakpa. 2018. Agronomic performance of four upland rice genotypes under rainfed condition. Afr. J. Food Agric. Nutr. Dev. 18(2):13304-13316.

Rahman, N M F, M A A Mamun, R Ahmed, M I Hossain, M A Qayum, MA Aziz, MA Hossain and M S Kabir. 2018. Stability and Adaptability Analysis of BRRI Developed Aus Varieties in Different Locations of Bangladesh. Bangladesh Rice J. 22 (1): 65-72, 2018.

Rai, H K and H S Kushwaha. 2008. Effect of planting dates and soil water regimes on growth and yield of upland rice. Oryza. 45:129-132.

Rao A N, Johnson D E, Sivaprasad B, J K Ladha and A M Mortimer. 2007. Weed management in directseeded rice. Adv. Agron. 93:153-255.
Roostaei, M, R Mohammadi and A Amri. 2014. Rank correlation among different statistical models in ranking of winter wheat genotypes. Crop J. 2: 154163.

Sakai, T, M C Duque, F A V Cabrera, C P Martínez and M Ishitani. 2010. Establishment of drought screening protocols for rice under field conditions. Acta Agronomica. 59(3):338-346.

Sandhu, N, R B Yadaw, B Chaudhary, H Prasai, K Iftekharuddaula, C Venkateshwarlu, A Annamalai, P Xangsayasane, K R Battan, M Ram, M T S Cruz, P Pablico, P C Maturan, K. A Raman, M Catolos and A Kumar. 2019. Evaluating the Performance of Rice Genotypes for Improving Yield and Adaptability Under Direct Seeded Aerobic Cultivation Conditions. Front. Plant Sci. 10:159.

Sanusan, S, A Polthanee, A Audebert, S Seripong and J Mouret. 2010. Suppressing weeds in direct-seeded lowland rainfed rice: Effect of cutting dates and timing of fertilizer application. Crop Protection 29: 927-935.

Shelley, I J, M T Nosaka, M K Nakata, M S Haque and Y Inukai. 2016. Rice Cultivation in Bangladesh: Present Scenario, Problems, and Prospects, J. Intl. Cooper. Agric. Dev. 14: 20-29.

Vanisree, S, K Swapna, D Raju, S Raju and M Sreedhar. 2013. Genetic variability and selection criteria in rice. J. biological and scientific opinion, 1(4):341346.

Yan, W. 2001. GGE Biplot-A Windows application for graphical analysis of multi-environment trial data and other types of two-way data. Agron. J. 93:11111118.

Yan, W, L A Hunt, Q L Sheng and Z Szlavnics. 2000. Cultivar evaluation and mega-environment investigation based on the GGE Biplot. Crop Sci. 40:597-605.

Zobel, R W, J M Wright, J H Gauch. 1988. Statistical analysis of yield trial. Agron. J. 80:388-393. 